\title{
Proteasome-mediated degradation of collagen III by cortisol in amnion fibroblasts
}

\author{
Yabing Mi1,2, Wangsheng Wang1,2, Jiangwen Lu1,2, Chuyue Zhang1,2, Yawei Wang3, Hao Ying 3 and Kang Sun 1,2 \\ 'Center for Reproductive Medicine, Ren Ji Hospital, School of Medicine, Shanghai Jiao Tong University, Shanghai, People's Republic of China \\ 2Shanghai Key Laboratory for Assisted Reproduction and Reproductive Genetics, Shanghai, People's Republic of China \\ 3Shanghai First Maternity and Infant Hospital, Tongji University School of Medicine, Shanghai, People's Republic of China \\ Correspondence should be addressed to K Sun: sungangrenji@sjtu.edu.cn
}

\begin{abstract}
Rupture of fetal membranes (ROM) can initiate parturition at both term and preterm. Collagen III in the compact layer of the amnion contributes to the tensile strength of fetal membranes. However, the upstream signals triggering collagen III degradation remain mostly elusive. In this study, we investigated the role of cortisol regenerated by $11 \beta$-hydroxysteroid dehydrogenase 1 (11 -HSD1) in collagen III degradation in human amnion fibroblasts with an aim to seek novel targets for the prevention of preterm premature ROM (pPROM)-elicited preterm birth. Human amnion tissue and cultured amnion tissue explants and amnion fibroblasts were used to study the regulation of collagen III, which is composed of three identical $3 \alpha 1$ chains (COL3A1), by cortisol. Cortisol decreased COL3A1 protein but not mRNA abundance in a concentrationdependent manner. Cortisone also decreased COL3A1 protein, which was blocked by $11 \beta$-HSD 1 inhibition. The reduction in COL3A1 protein by cortisol was not affected by a transcription inhibitor but was further enhanced by a translation inhibitor. Autophagic pathway inhibitor chloroquine or siRNA-mediated knock-down of ATG7, an essential protein for autophagy, failed to block cortisol-induced reduction in COL3A1 protein abundance, whereas proteasome pathway inhibitors MG132 and bortezomib significantly attenuated cortisol-induced reduction in COL3A1 protein abundance. Moreover, cortisol increased COL3A1 ubiquitination and the reduction of COL3A1 protein by cortisol was blocked by PYR-41, a ubiquitin-activating enzyme inhibitor. Conclusively, cortisol regenerated in amnion fibroblasts may be associated with ROM at parturition by reducing collagen III protein abundance through a ubiquitin-proteasome pathway.
\end{abstract}

Journal of Molecular Endocrinology (2018) 60, 45-54

\section{Introduction}

Preterm birth (<37 weeks) occurs in approximately $10 \%$ of all pregnancies, which claims millions of neonatal casualties each year (Blencowe et al. 2012). Preterm premature rupture of fetal membranes (pPROM) accounts for about one-third of the preterm births (Slattery \& Morrison 2002). Therefore, delineating the mechanism underlying membrane rupture may provide novel targets for the prevention of preterm birth. Human fetal membranes are composed of amnion and chorion. The tensile strength of the fetal membranes mainly derives from the collagen contents in the compact layer of the amnion, which is predominantly constituted of types I and III together with small amounts of types IV, V and VI collagens (Malak et al. 1993, Parry \& Strauss 1998, 
Oyen et al. 2006). The quantitatively major collagen types I and III form parallel collagen bundles, while the minor collagen types IV, V and VI provide a scaffold for the assembly of other mesenchymal components, form filament connections with types I and III collagens or provide an additional anchoring function for types I and III (Bryant-Greenwood 1998). Previous studies have shown that the abundance of collagens in the fetal membranes decreases with advancing gestational age, and further decreases in pPROM (Skinner et al. 1981, Kumar et al. 2016), suggesting that decreased collagen abundance in the fetal membranes plays a crucial role in the ROM. The causes for collagen reduction are believed to be largely ascribed to extracellular degradation by matrix metalloproteinases (MMPs) (Athayde et al. 1998, Strauss 2013), whereas very little is known about collagen degradation through lysosome and proteasome pathways.

The fetal membranes possess the largest cortisolregenerating capacity among fetal tissues in late gestation (Murphy 1981). The expression of cortisol-regenerating

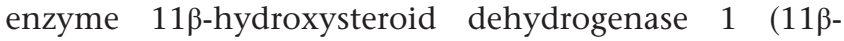
HSD1) has been found in virtually all cell types in the membranes (Sun \& Myatt 2003) with its expression increasing with gestational age (Alfaidy et al. 2003). Intriguingly, in contrast to the conventional negative feedback of products on enzymes, cortisol induces 11ßHSD1 expression in the fetal membranes, thus forming a local feedforward loop of cortisol regeneration toward the end of gestation (Sun \& Myatt 2003, Yang et al. 2007). The functional role of this unique feature of cortisol regeneration in the fetal membranes remains elusive. Accumulating evidence indicates that in addition to the induction of prostaglandin synthesis (Casey et al. 1985, Zhu et al. 2009, Wang et al. 2015), cortisol regenerated by $11 \beta$-HSD1 may also be involved in extracellular matrix structure remodeling via induction of amnion epithelial cell apoptosis (Wang et al. 2016), inhibition of collagen cross-linking enzyme lysyl oxidase (Liu et al. 2016) and degradation of collagen I in amnion fibroblasts (Mi et al. 2017). Of interest, autophagic pathway is revealed to be associated with cortisol-induced collagen I degradation
(Mi et al. 2017). However, we are unclear whether cortisol regeneration is also engaged in the degradation of collagen III, another major collagen type in the amnion compact layer. Given the reported roles of glucocorticoids in lysosome and proteasome-mediated protein degradation in a number of tissues including the amnion (Hopgood et al. 1981, Hasan et al. 2012, Yao et al. 2013, Mi et al. 2017), we hypothesize that cortisol regeneration by $11 \beta$-HSD1 may also participate in collagen III degradation through these pathways in amnion fibroblasts, the major source of collagens in the amnion compact layer, thereby devastating the major collagen bundles in the amnion resulting in the rupture of membranes. Here, we examined this hypothesis in human amnion tissue and fibroblasts.

\section{Materials and methods}

\section{Collection of human fetal membranes}

Human fetal membranes were obtained from uncomplicated term (38-40 weeks) pregnancies after elective cesarean section without labor (non-labor) or after vaginal delivery with spontaneous rupture of the membranes (labor). Written informed consent was obtained from the participating patients under a protocol approved by the Ethics Committee of Ren Ji Hospital, School of Medicine, Shanghai Jiao Tong University. Pregnancies with complications such as preeclampsia, fetal growth restriction, gestational diabetes and chorioamnionitis were excluded from this study.

\section{Extraction of protein from the human amnion tissue}

To study the changes of collagen III abundance in the amnion tissue in parturition, the fetal membranes were collected from deliveries with spontaneous rupture of membranes at labor $(n=7)$ or without labor at elective c section $(n=9)$. The demographic characteristics of patients are given in Table 1 . The amnion was peeled off the chorion and was cut within $5 \mathrm{~cm}$ of the spontaneous

Table 1 Demographic characteristics of patients with spontaneous labor and rupture of membranes or without labor at elective c-section.

\begin{tabular}{|c|c|c|c|}
\hline & Non-labor $(n=9)$ & Labor $(n=7)$ & $P$-value \\
\hline Maternal age (years) & $31.73 \pm 0.87$ & $30.25 \pm 1.16$ & 0.31 \\
\hline $\mathrm{BMI}$ & $21.34 \pm 0.73$ & $20.55 \pm 0.65$ & 0.36 \\
\hline Gravidity, median (range) & $2(1-4)$ & $2(1-4)$ & NS \\
\hline Parity, median (range) & $1(1-2)$ & $1(1-2)$ & NS \\
\hline Gestational age (weeks) & $38.91 \pm 0.16$ & $39.75 \pm 0.25$ & 0.17 \\
\hline Birth weight (g) & $3511.67 \pm 82.25$ & $3190.00 \pm 117.58$ & 0.45 \\
\hline
\end{tabular}


or artificial rupture zones of the membranes, and ground in liquid nitrogen. After homogenization, the ground tissue was lysed in ice-cold radioimmune-precipitation assay (RIPA) lysis buffer (Active Motif, Carlsbad, CA, USA) containing a protease inhibitor cocktail (Sigma) and centrifuged at $13,000 \mathrm{~g}, 10 \mathrm{~min}, 4^{\circ} \mathrm{C}$. Protein in the supernatant was collected for collagen III protein determination with Western blotting.

\section{Preparation of human amnion tissue explants}

Human amnion tissue explants were prepared from the amnion collected from patients with elective c section without labor at term $(n=3)$. The amnion was cut in circles using a 6-mm skin biopsy puncher and then placed in Falcon cell culture inserts (Becton Dickinson, Franklin Lakes, NJ, USA) in a 6-well plate in culture medium containing 1:1 mixture of Ham's F12: Dulbecco's Modified Eagle Medium (DMEM), 10\% fetal bovine serum (FBS) and 1\% antibiotics (Life Technologies). The explants were equilibrated at $37^{\circ} \mathrm{C}$ in $5 \% \mathrm{CO}_{2} / 95 \%$ air for $24 \mathrm{~h}$. The explants were then treated with cortisol $(1 \mu \mathrm{M}$; Sigma) in phenol red/serum-free medium for $24 \mathrm{~h}$ and the explants were collected for protein extraction as described above for collagen III protein determination with Western blotting.

\section{Preparation of human amnion fibroblasts}

Human amnion fibroblasts were isolated from the amnion collected from patients with elective c section without labor at term $(n=43)$. After peeling off the chorion, the amnion tissue was digested twice with $0.125 \%$ trypsin (Life Technologies) for $20 \mathrm{~min}$ to remove epithelial cells, and then washed vigorously to remove residual epithelial cells. The remaining amnion tissue was digested with $0.1 \%$ collagenase (Sigma) for $18 \mathrm{~min}$ to release the fibroblasts from the mesenchymal tissue. The digestion medium was centrifuged at $1000 \mathrm{~g}, 10 \mathrm{~min}, 4^{\circ} \mathrm{C}$, and the pellet was re-suspended in DMEM and layered on Percoll (GE Healthcare Bio-Sciences) gradients (5, 20, 40 and $60 \%$ ) for further purification of the fibroblasts. After washing, the purified fibroblasts were cultured at $37^{\circ} \mathrm{C}$ in $5 \% \mathrm{CO}_{2} / 95 \%$ air in DMEM containing $10 \%$ FBS plus $1 \%$ antibiotics (Life Technologies). The identity of cells was verified by immunofluorescent staining for mesenchymal cell marker vimentin, epithelial marker cytokeratin and leukocyte marker CD45, and more than $95 \%$ of the cells were vimentin-positive.

\section{Immunofluorescent staining of human amnion fibroblasts}

The cells were plated in Chamber Polystyrene Vessels (BD Falcon, Franklin Lakes, NJ, USA). Three days after culture in DMEM containing 10\% FBS, the cells were fixed with $4 \%$ paraformaldehyde and permeabilized with $0.4 \%$ Triton X-100 for immunofluorescence staining. The cells were blocked with normal goat serum (Jackson ImmunoResearch Laboratories) and then incubated with primary antibodies at 1:100 dilutions against vimentin (Santa Cruz Biotechnology), cytokeratin (Santa Cruz Biotechnology) and CD45 (Abcam) overnight at $4^{\circ} \mathrm{C}$. After washing with PBS, Alexa Fluor 488 (green)- and Alexa Fluor 594 (red)-labeled secondary antibodies (1:100; Proteintech) were applied in darkness at room temperature for $2 \mathrm{~h}$. Nuclei were counterstained with 4',6-diamidino-2phenylindole (DAPI, blue color) $(1 \mu \mathrm{g} / \mathrm{mL})$. The staining was examined using a fluorescence microscope (Zeiss).

\section{Treatment of human amnion fibroblasts}

Three days after plating, amnion fibroblasts were treated with the following reagents in phenol red/FBS-free culture medium for $24 \mathrm{~h}$ unless specified. To examine concentration-dependent effects of cortisol on collagen III mRNA and protein abundance, cortisol (0.01, 0.1 and $1 \mu \mathrm{M})$ was added to fibroblasts. To examine whether the effect of cortisol on collagen III abundance occurred at the transcriptional or translational level, fibroblasts were treated with cortisol $(1 \mu \mathrm{M})$ in the presence or absence of the transcription inhibitor 5,6-dichloro-1-beta-Dribofuranosylbenzimidazole (DRB) $(1 \mu \mathrm{M}$; Sigma) or the translation inhibitor cycloheximide (CHX) $(1 \mu \mathrm{M}$; Sigma). To examine the role of glucocorticoid receptor (GR) in the regulation of collagen III abundance by cortisol, the cells were treated with cortisol $(1 \mu \mathrm{M})$ in the presence or absence of GR antagonist RU486 (1 $\mu \mathrm{M}$, Sigma) or small interfering RNA (siRNA)-mediated knock-down of GR. To examine the involvement of $11 \beta-H S D 1$ in the regulation of collagen III abundance, fibroblasts were treated with cortisone $(5 \mu \mathrm{M}$; Sigma) in the presence or absence of $11 \beta$-HSD1 inhibitor $10 \mathrm{j}(1 \mu \mathrm{M}$; Millipore $)$ or siRNAmediated knock-down (GenePharma, Shanghai, China) of $11 \beta-H S D 1$. To examine the involvement of lysosome and proteasome pathways in the degradation of collagen III, fibroblasts were treated with cortisol $(1 \mu \mathrm{M})$ in the presence or absence of a lysosome pathway inhibitor chloroquine (CQ) $(50 \mu \mathrm{M}$; Sigma) or proteasome pathway inhibitors MG132 (10nM; Selleck, Houston, TX, USA) 
and bortezomib (50 nM; Selleck) or a ubiquitin-activating Enzyme E1 inhibitor PYR-41 $(5 \mu \mathrm{M}$; Selleck). The involvement of lysosome pathway was further examined with siRNA-mediated knock-down of autophagy-related protein 7 (ATG7) (Comincini et al. 2013). After the aforementioned treatments, collagen III mRNA or protein abundance was determined with quantitative real-time PCR (qRT-PCR) or Western blotting.

\section{Transfection of siRNA in amnion fibroblasts with electroporation}

To study the role of $11 \beta$-HSD1 and GR in the regulation of collagen III by glucocorticoids, fibroblasts were transfected with 50 nM siRNA (GenePharma) against 11ß-HSD1 (5'-CACCAACACUUCUUUGAAUTT-3') or GR (5'-GCAGCCAGAUCUGUCCAAATT- $\left.3^{\prime}\right)$. To study the role of ATG7 in cortisol-induced COL3A1 protein degradation, fibroblasts were transfected with 50nM siRNA (GenePharma) targeting ATG7 (5'-GCCUCUCUAUGAGUUUGAATT-3'). Randomly scrambled siRNA (5-UUCUCCGAACGUGUCACGUTT-3) served as control. The cells were transfected using an electroporator at $175 \mathrm{~V}$ for $5 \mathrm{~ms}$ as described previously (Wang et al. 2015) and then incubated in DMEM containing 10\% FBS and 1\% antibiotics for three days before treatments. The efficiency of knock-down was assessed by measuring target proteins with Western blotting, and was shown to be 75,70 and $65 \%$ for 11 $\beta$-HSD1, GR and ATG7, respectively.

\section{Quantitative real-time PCR}

After treatment, total RNA was extracted from the cells and reverse-transcribed to cDNA using a commercial kit (TaKaRa). Since collagen III consists of three identical $\alpha 1$ chains (COL3A1) ], the amounts of COL3A1 mRNA were determined by qRT-PCR using the above-transcribed cDNA and power SYBR Premix Ex Taq (TaKaRa) as described previously (Wang et al. 2015). The absolute mRNA abundance in each sample was calculated from a standard curve setup using serial dilutions of known amounts of specific templates generated by PCR against corresponding cycle threshold values. Housekeeping gene GAPDH was amplified in parallel as an internal control. The primer sequences are as follows: COL3A1, forward 5'-CCTGCTGGAGAGCGTGGTGC, reverse 5'-TGACTTCCGGGAGGCCCTGG; GAPDH, forward 5'-CСССТCTG CTGATGCCCCCA-3', reverse 5'-TGACCTTGGCCAGGGGTGCT-3'. The ratio of the target gene over GAPDH in each sample was obtained as an indication of the target gene expression.

\section{Western blotting}

After treatment, the cells were lysed in ice-cold RIPA lysis buffer (Active Motif) containing a protease inhibitor cocktail (Sigma). After determination of protein concentration, the extracted protein was analyzed with Western blotting following a standard protocol using primary antibodies against COL3A1 (1:1000, Novus, Littleton, CO, USA), COL1A1 (a major chain of collagen I, 1:1000, Novus), ATG7 (1:1000, Cell Signaling), GR (1:1000, Santa Cruz Biotechnology) and 11ß-HSD1 (1:500, Abcam). Internal loading controls were probed with antibodies against GAPDH (1:5000, Proteintech, Rosemont, IL, USA) or $\beta$-Actin (1:10000, Proteintech). The bands were visualized using a G-Box iChemi Chemiluminescence image capture system (Syngene, Cambridge, UK). The ratio of band intensities of COL3A1, COL1A1, ATG7, GR and 11 $\beta$-HSD1 over GAPDH or $\beta$-actin was obtained, respectively, as a measure of target protein abundance.

\section{Examination of COL3A1 ubiquitination}

To examine the ubiquitination of COL3A1 protein, the fibroblasts were treated with cortisol $(1 \mu \mathrm{M})$ in the presence of MG132 (10 nM) for $24 \mathrm{~h}$ and then lysed in non-denaturing cell lysis buffer (Cell Signaling) containing 1 mM PMSF (Cell Signaling) on ice. A small amount of lysate was aspirated to serve as an input control and the remaining lysate was incubated with protein $\mathrm{A} / \mathrm{G}$ agarose beads for $1.5 \mathrm{~h}$ at $4^{\circ} \mathrm{C}$. After centrifugation at $60 \mathrm{~g}, 5 \mathrm{~min}, 4^{\circ} \mathrm{C}$, the supernatant was divided into two parts for further incubation with COL3A1 antibody $(4 \mu \mathrm{g})$ or non-immune rabbit IgG $(4 \mu \mathrm{g})$ overnight at $4^{\circ} \mathrm{C}$. Protein $\mathrm{A} / \mathrm{G}$ agarose beads were then added again for further incubation for $1.5 \mathrm{~h}$ at $4^{\circ} \mathrm{C}$. After centrifugation at $60 \mathrm{~g}, 5 \mathrm{~min}, 4^{\circ} \mathrm{C}$, the beads in the pellet were washed with the non-denaturing cell lysis buffer. Then, $25 \mu \mathrm{L}$ of $2 \times$ Western blotting loading buffer was added to the washed beads and the solution was boiled for $5 \mathrm{~min}$. After centrifugation at $13,000 \mathrm{~g}, 30 \mathrm{~s}, 25^{\circ} \mathrm{C}$, the supernatant was collected for analysis with Western blotting along with the input control. The ubiquitinated COL3A1 was detected with an antibody against ubiquitin (1:1000, Cell Signaling).

\section{Statistical analysis}

All data are reported as mean \pm s.E.M. The number in each study represents separate experiments using amnion cells 
prepared from different pregnancies. Statistical analysis was performed with paired or unpaired Student's $t$-test or one-way ANOVA test followed by the Newman-Keuls Multiple Comparison Test where appropriate. Significance was set at $P<0.05$.

\section{Results}

\section{Reduction in COL3A1 protein abundance in the human amnion tissue at parturition}

The demographic characteristics of patients with spontaneous labor and rupture of membranes or without labor at elective c section are given in Table 1 . COL3A1 protein abundance in the amnion tissue was significantly decreased in labor with spontaneous rupture of membranes when compared with elective c section without labor (Fig. 1A). Heterogeneity in COL3A1 protein abundance was observed within both groups. We are not

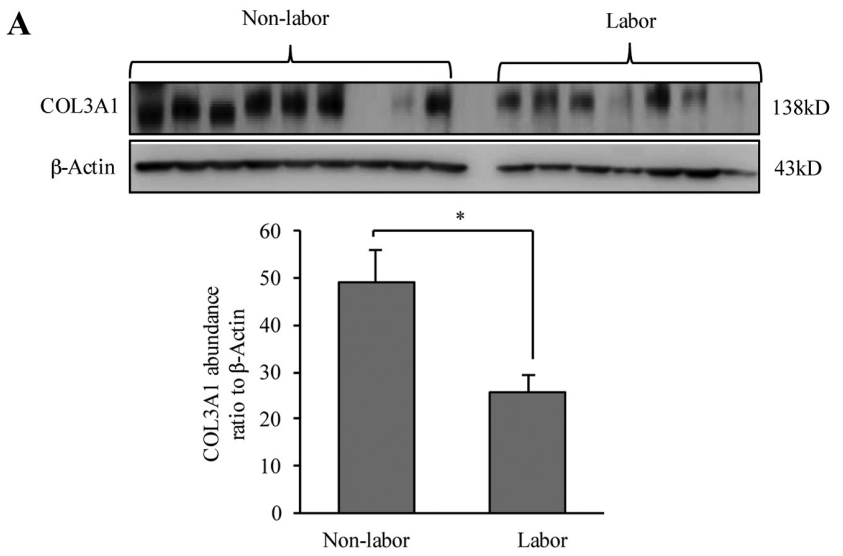

B
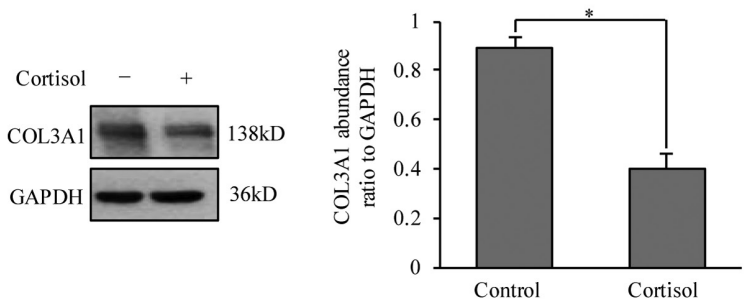

Figure 1

Changes of COL3A1 protein abundance in human amnion tissue. (A) Protein abundance of COL3A1 in human amnion tissue was decreased following spontaneous rupture of membranes at term parturition (labor) $(n=7)$ in comparison with elective c section without labor at term (non-labor) $(n=9)$. (B) Cortisol $(1 \mu \mathrm{M}, 24 \mathrm{~h})$ reduced COL3A1 protein abundance in cultured human amnion tissue explants $n=3$. The left panel of $B$ denotes the representative Western blots. Data are mean \pm S.E.M. Statistical analysis was performed with unpaired $(A)$ or paired $(B)$ Student's $t$-test. ${ }^{*} P<0.05$ clear what causes the heterogeneity at present. It may be due to some subclinical unidentified reasons.

\section{Reduction in COL3A1 protein abundance in human amnion tissue explants by cortisol}

Treatment of human amnion tissue explants with cortisol $(1 \mu \mathrm{M})$ significantly decreased COL3A1 protein abundance (Fig. 1B), indicating that cortisol regeneration may contribute to the reduction of COL3A1 protein in the amnion at parturition.

\section{Cortisol decreases COL3A1 protein but not mRNA in human amnion fibroblasts}

Immunofluorescent staining showed that more than 95\% of the cells isolated from the amnion are vimentin-positive fibroblasts rather than cytokeratin-positive epithelial cells or CD45-positive leukocytes (Fig. 2). Treatment of amnion fibroblasts with cortisol $(0.01,0.1$ and $1 \mu \mathrm{M})$ had no effect on COL3A1 mRNA, but decreased COL3A1 protein in a concentration-dependent manner (Fig. 3A). Time course $(3,6,12$ and $24 \mathrm{~h})$ analysis confirmed the lack of effect of cortisol $(1 \mu \mathrm{M})$ on COL3A1 mRNA and also the decreases in COL3A1 protein by cortisol at 12 and $24 \mathrm{~h}$ (Fig. 3B). Cortisol $(1 \mu \mathrm{M})$-induced decreases in COL3A1 protein were still observed in the presence of the mRNA transcription inhibitor DRB ( $1 \mu \mathrm{M})$ (Fig. 3C) and was further enhanced by the protein translation inhibitor CHX $(1 \mu \mathrm{M})$ (Fig. 3D). These data suggest that cortisol reduces COL3A1 protein abundance at the post-translational level.

\section{Participation of GR in cortisol-induced decreases in COL3A1 protein in human amnion fibroblasts}

Treatment of amnion fibroblasts with cortisol $(1 \mu \mathrm{M})$ in the presence of either GR antagonist RU486 (1 $\mu \mathrm{M})$ (Fig. 4A) or siRNA-mediated knock-down of GR (Fig. 4B) blocked the reduction in COL3A1 protein by cortisol, indicating the participation of GR in cortisol-induced reduction in COL3A1 protein.

\section{Participation of 11p-HSD1 in cortisone-induced decreases in COL3A1 protein in human amnion fibroblasts}

Treatment of amnion fibroblasts with cortisone $(5 \mu \mathrm{M})$ in the presence of either $11 \beta$-HSD1 inhibitor $10 \mathrm{j}(1 \mu \mathrm{M})$ (Fig. 4C) or siRNA-mediated knock-down of 11ß-HSD1 (Fig. 4D) significantly attenuated cortisone-induced 

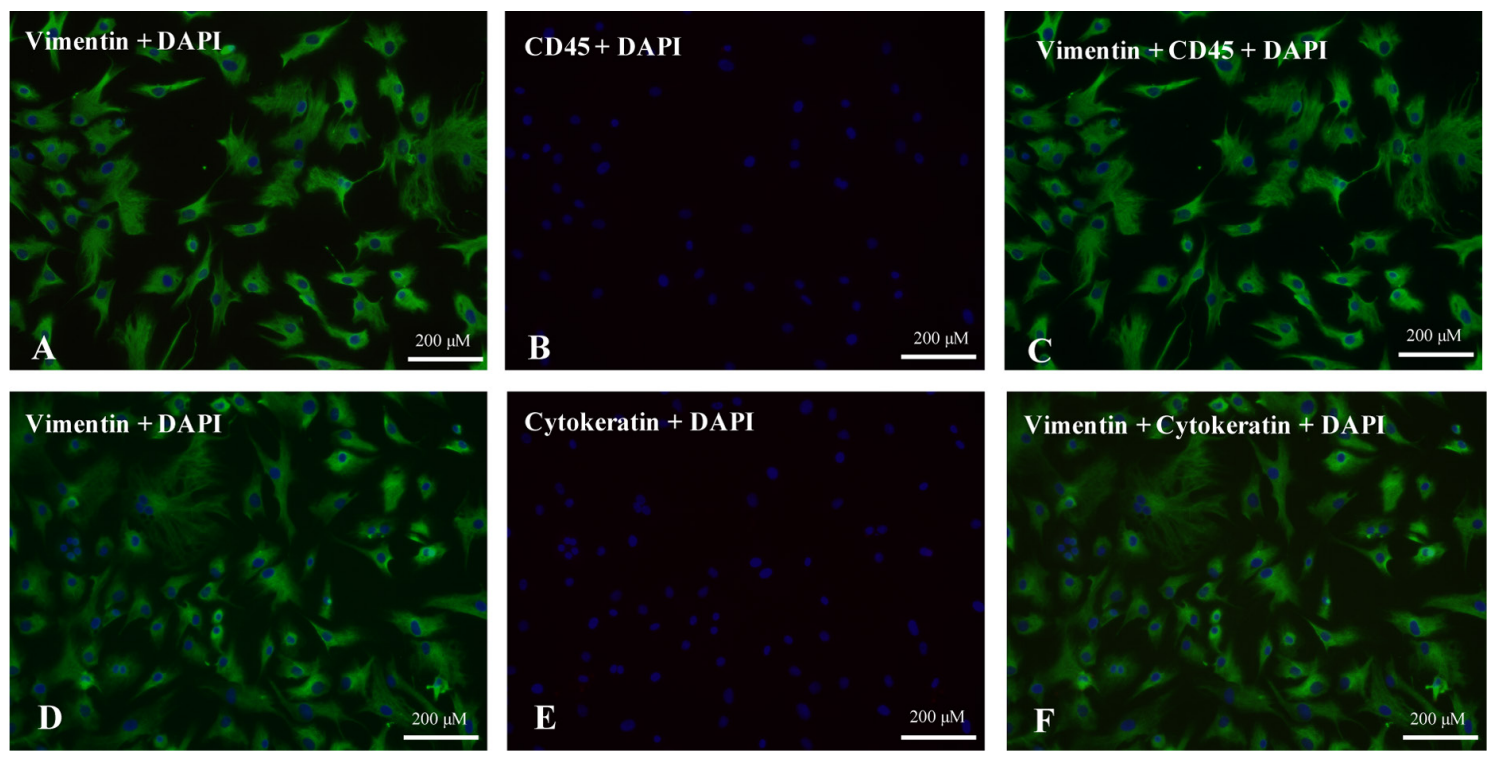

Figure 2

Immunofluorescent staining of cultured amnion cells with antibodies against vimentin (green; A, C, D, F), cytokeratin (red; E and F) and CD45 (red; B and C). The nuclei were stained with DAPI (blue).

decreases in COL3A1 protein, indicating the involvement of $11 \beta$-HSD1 in the downregulation of COL3A1 protein in amnion fibroblasts.

\section{Cortisol decreases COL3A1 protein via proteasome but not lysosome pathway in human amnion fibroblasts}

The lysosome pathway inhibitor CQ $(50 \mu \mathrm{M})$ (Fig. 5A) or siRNA-mediated knock-down of ATG7 (Fig. 5B) failed to block cortisol $(1 \mu \mathrm{M})$-induced reduction in COL3A1 protein, whereas the same treatments reversed cortisol $(1 \mu \mathrm{M})$-induced reduction in COL1A1 protein as reported earlier (Mi et al. 2017). The proteasome pathway inhibitor MG132 (10nM) (Fig. 5A) could block cortisol (1 $\mu \mathrm{M})$ induced reduction in COL3A1 protein but not the reduction in COL1A1 protein. Furthermore, bortezomib (50 nM) (Fig. 5C), another proteasome pathway inhibitor, and PYR-41 $(5 \mu \mathrm{M})$, a ubiquitin-activating Enzyme E1 inhibitor (Fig. 5D), could also block cortisol-induced reduction in COL3A1 protein. The ubiquitination of COL3A1 was increased by cortisol $(1 \mu \mathrm{M})$ in the presence of MG132 (10 nM) in amnion fibroblasts (Fig. 6). However, a single band was observed above $170 \mathrm{kD}$ in the sample precipitated by the COL3A1 antibody, suggesting that uniform ubiquitination of COL3A1 occurred. These data suggest that the ubiquitin-proteasome pathway rather than the lysosome pathway is involved in the degradation of COL3A1 by cortisol in human amnion fibroblasts.

\section{Discussion}

It remains a mystery why the fetal membranes evolve such an extraordinary capability of cortisol regeneration by 11ß-HSD1 (Murphy 1977, 1981). In this study, we have demonstrated that cortisol regeneration by $11 \beta-H S D 1$ in human amnion fibroblasts participates in the degradation of COL3A1 protein via activation of the ubiquitin-proteasome system. Since the concentration of cortisol can reach up to $5 \mu \mathrm{M}$ locally in the amnion tissue at parturition (Wang et al. 2015), the concentration of cortisol used in this study is thus physiologically relevant. In light of a previous study showing that glucocorticoids inhibit collagen expression in human amnion epithelial cells (Guller et al. 1995) and our recent findings that cortisol regenerated by $11 \beta-H S D 1$ degrades COL1A1 via an autophagic pathway (Mi et al. 2017) and decreases the expression of collagen cross-linking enzyme lysyl oxidase (Liu et al. 2016), we believe that local cortisol regeneration by $11 \beta-H S D 1$ may play a pivotal role in the membrane rupture at parturition by reducing both collagen abundance and cross-linking. It has been noted for a long time that excessive glucocorticoids cause skin atrophy through collagen degradation (Schoepe et al. 2006) and inhibition of $11 \beta$-HSD 1 improves agingrelated skin conditions (Tiganescu et al. 2013). Given the demonstrated effects of cortisol regeneration on collagen degradation and cross-linking, we postulate that inhibition of $11 \beta$-HSD1 may also provide a potential 
A

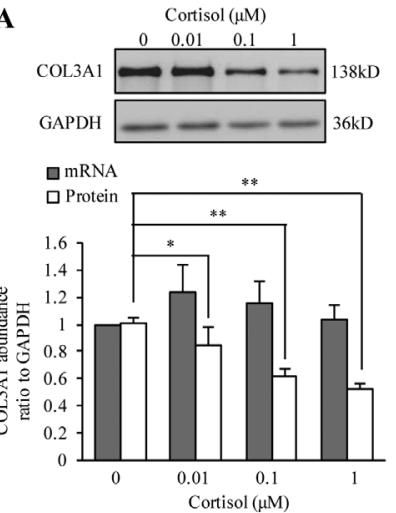

C

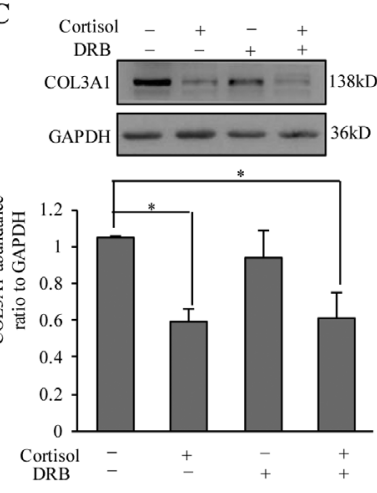

B
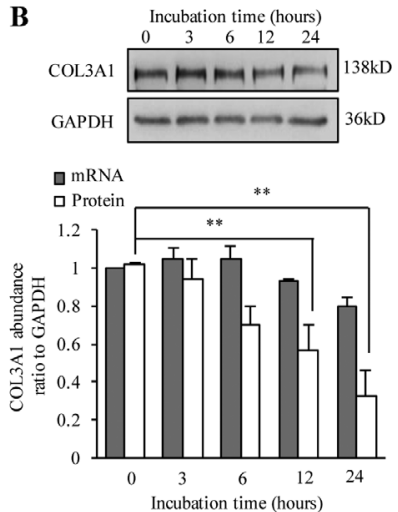

D
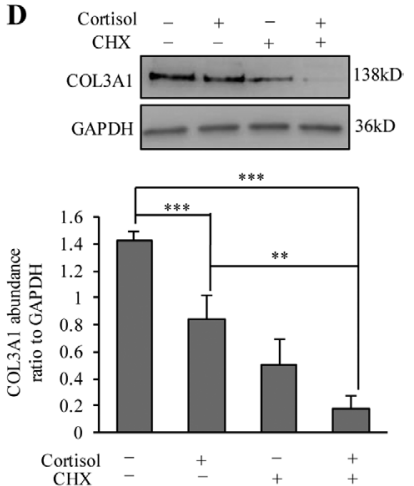

Figure 3

Effects of cortisol on COL3A1 mRNA and protein abundance in human amnion fibroblasts. (A) Effects of cortisol (0, $0.01,0.1$ and $1 \mu \mathrm{M}, 24 \mathrm{~h})$ on COL3A1 mRNA $(n=6)$ and protein $(n=6)$ abundance. (B) Time course effects of cortisol $(1 \mu \mathrm{M} ; 0,3,6,12$ and $24 \mathrm{~h})$ on COL3A1 mRNA $(n=5)$ and protein $(n=5)$ abundance. (C and D) Effect of mRNA transcription inhibitor DRB $(1 \mu \mathrm{M}, n=4)$ or protein translation inhibitor CHX $(1 \mu \mathrm{M}$, $n=5)$ on cortisol $(1 \mu \mathrm{M} ; 24 \mathrm{~h})$-induced decreases in COL3A1 protein abundance. The upper panels of $A, B, C$ and $D$ denote representative Western blots. Data are mean \pm S.E.M. Statistical analysis was performed with one-way ANOVA test. ${ }^{*} P<0.05,{ }^{* * P} P<0.01, * * * P<0.001$.

therapeutic intervening approach in the prevention of premature preterm rupture of membranes.

Amnion fibroblasts, unlike amnion epithelial cells, are resistant to apoptosis induced by cortisol (Wang et al. 2016). It is thus unlikely that the degradation of collagens by cortisol is a consequence of apoptotic effects induced by cortisol in amnion fibroblasts. Although the data in the current study were obtained under cultured conditions in vitro, we believe that they are a reflection of in vivo situations since the degradation of COL3A1 by cortisol was reproducible in amnion tissue explants and was consistent with changes of COL3A1 abundance in the amnion tissue obtained from patients as well.

Our findings that cortisol degrades COL1A1 and COL3A1 through lysosome and proteasome pathways, respectively, appear to reconcile with previous studies showing that both ubiquitin-proteasome and autophagic

A

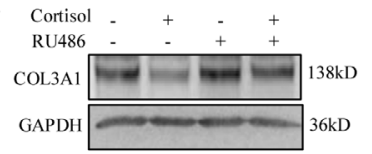

B
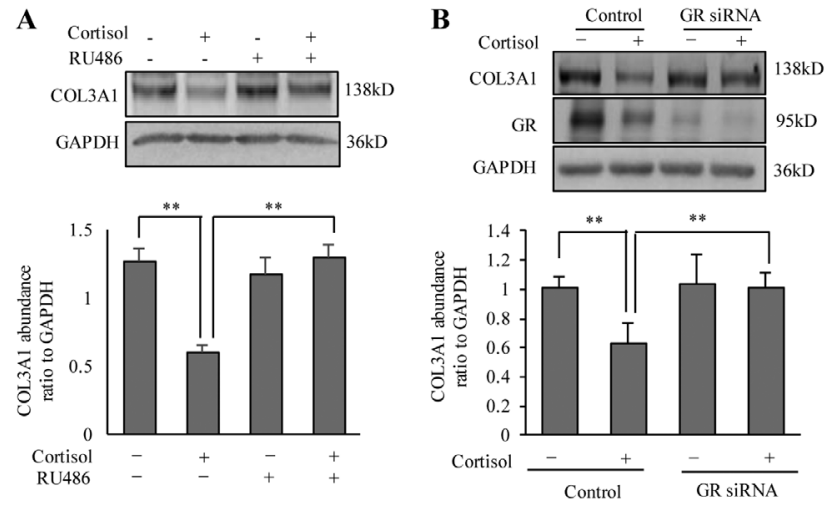

C
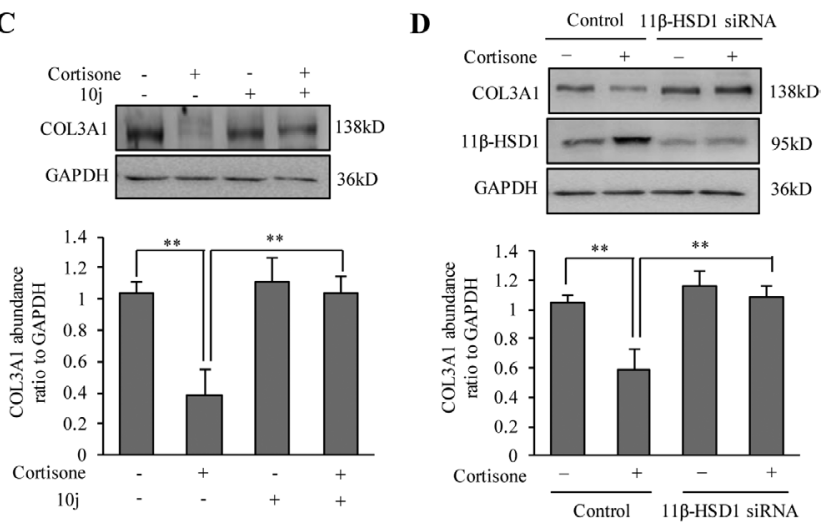

Figure 4

Role of GR and 11 $\beta$-HSD1 in glucocorticoid-induced decreases in COL3A1 protein abundance in human amnion fibroblasts. (A) GR antagonist RU486 $(1 \mu \mathrm{M})$ blocked cortisol $(1 \mu \mathrm{M}, 24 \mathrm{~h})$-induced decreases in COL3A1 protein abundance $n=5$. (B) siRNA-mediated knock-down of GR attenuated cortisol ( $1 \mu \mathrm{M}, 24 \mathrm{~h})$-induced decreases in COL3A1 protein abundance $n=5$. (C) $11 \beta$-HSD1 inhibitor $10 \mathrm{j}(1 \mu \mathrm{M})$ blocked cortisone $(5 \mu \mathrm{M}, 24 \mathrm{~h})$-induced decreases in COL3A1 protein abundance $n=5$. (D) siRNA-mediated knock-down of $11 \beta$-HSD1 attenuated cortisone $(5 \mu \mathrm{M}, 24 \mathrm{~h})$-induced decreases in COL3A1 protein abundance $n=4$. The upper panels of A, B, C and D denote representative Western blots. Data are mean \pm S.E.M. Statistical analysis was performed with one-way ANOVA test. ${ }^{*} * P<0.01$.

lysosome pathways are activated during ROM (Cao et al. 2017, Zhao et al. 2017). Although collagens I and III comprise the backbone of the mesenchymal structure of the compact layer in the amnion, they may differ slightly in their functional roles in ECM remodeling. According to a report by Goel and coworkers, COL3A1 is elastic but COL1A1 is more rigid in the vasculature (Goel et al. 2013). However, we are unclear why cortisol adopts differential mechanisms in the degradation of COL1A1 and COL3A1, which may be ascribed to the structure differences of these two types of collagen chains. This study presented evidence for the proteasome-mediated degradation of COL3A1 protein by cortisol in human amnion fibroblasts and the lysosomal pathway can be excluded in the degradation of COL3A1 protein by cortisol because the proteasome 

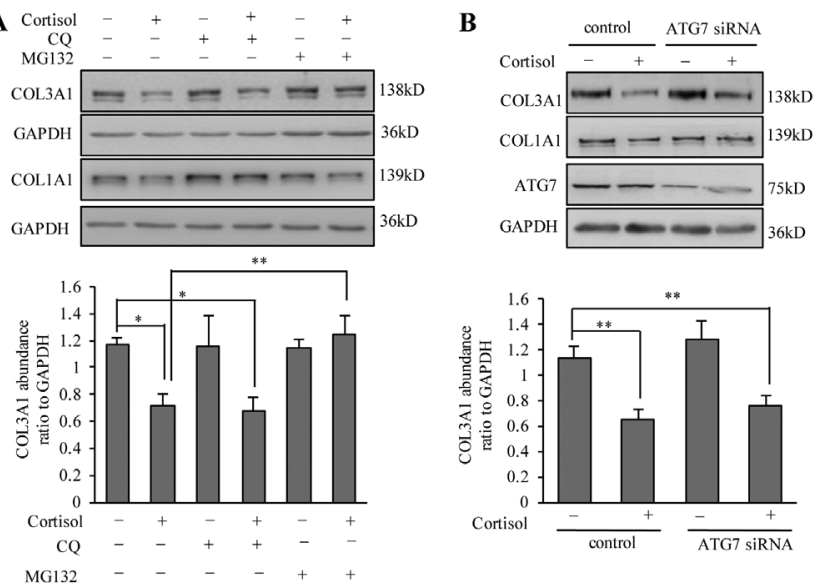

C

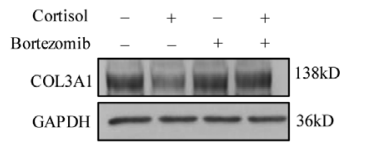

D
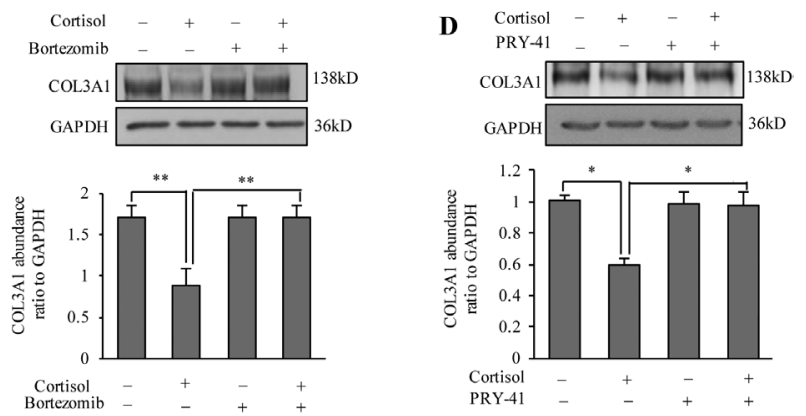

Figure 5

Effects of proteasome and lysosome pathway inhibitors on cortisolinduced decreases in COL3A1 protein abundance in human amnion fibroblasts. (A) Proteasome pathway inhibitor MG132 (10 nM) blocked cortisol ( $1 \mu \mathrm{M}, 24 \mathrm{~h})$-induced reduction in COL3A1 but not COL1A1 protein abundance, whereas the lysosome pathway inhibitor CQ $(50 \mu \mathrm{M})$ blocked cortisol ( $1 \mu \mathrm{M}, 24 \mathrm{~h})$-induced reduction in COL1A1 but not COL3A1 protein abundance $n=5$. (B) siRNA-mediated knock-down of ATG7 blocked cortisol $(1 \mu \mathrm{M})$-induced reduction in COL1A1 but not COL3A1 protein abundance $n=4$. (C) Bortezomib $(50 \mathrm{nM})$ blocked cortisol $(1 \mu \mathrm{M}, 24 \mathrm{~h})$-induced reduction in COL3A1 protein abundance $(n=5)$. (D) Ubiquitin-activating Enzyme E1 inhibitor PYR-41 $(5 \mu \mathrm{M})$ blocked cortisol $(1 \mu \mathrm{M}, 24 \mathrm{~h})$-induced reduction in COL3A1 protein abundance $n=5$. Upper panels of A, B, C and D denote representative Western blots. Data are mean \pm S.E.M. Statistical analysis was performed with one-way ANOVA test. $* P<0.05, * * P<0.01$.

inhibitors MG132 and bortezomib could reverse the reduction in COL3A1 protein by cortisol, whereas the lysosomal inhibitor CQ or siRNA-mediated knock-down of ATG7 failed to block the reduction in COL3A1 protein by cortisol despite successful blockade of the reduction in cortisol-induced COL1A1 protein abundance. The involvement of proteasome pathway is further supported by the findings with a broad spectrum inhibitor of ubiquitination enzymes E1 PYR-41 (Inobe \& Matouschek 2014) and the increase in COL3A1 ubiquitination upon cortisol treatment. Ubiquitination of proteins is normally associated with proteasome degradation of cellular proteins (Thrower et al. 2000). Although GR is shown to mediate the degradation of COL3A1 protein by cortisol,
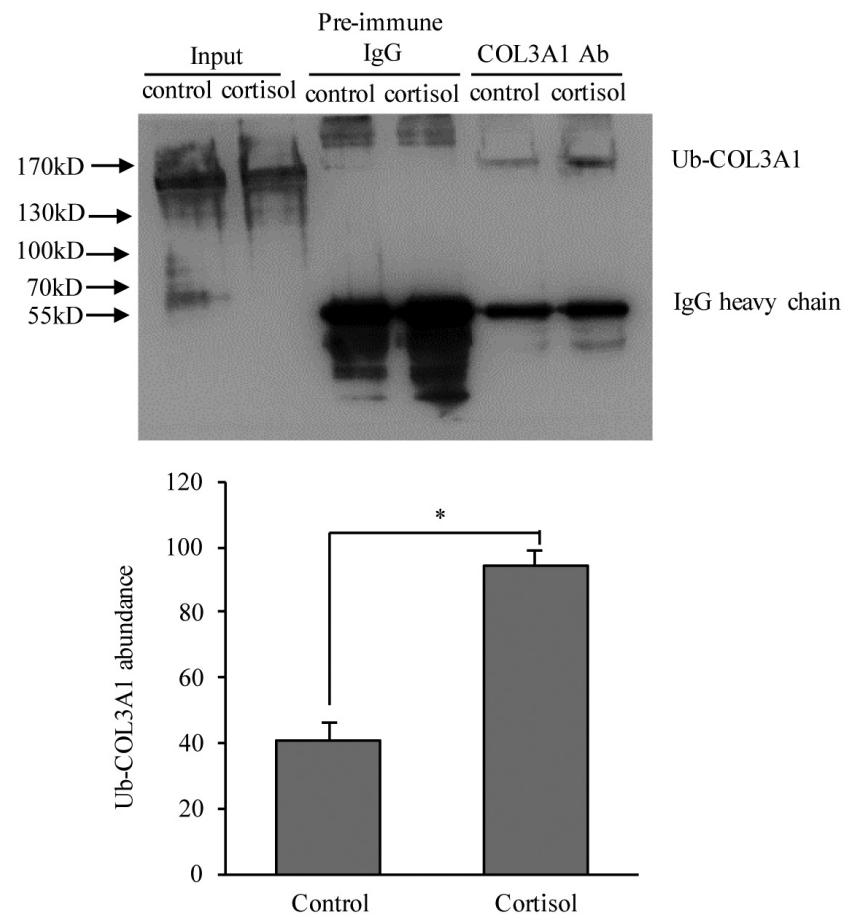

Figure 6

COL3A1 ubiquitination by cortisol in human amnion fibroblasts. Cortisol $(1 \mu \mathrm{M}, 24 \mathrm{~h})$ increased the ubiquitination of COL3A1 in the presence of MG132 in human amnion fibroblasts as revealed by Western blotting $n=3$. The upper panel denotes representative Western blots. Data are mean \pm s.E.M. Statistical analysis was performed with paired Student's $t$-test. ${ }^{*} P<0.05$.

how cortisol activates the ubiquitin-proteasome pathway via GR remains to be investigated in the future.

It should be kept in mind that multiple factors may contribute to the reduction of collagens in the fetal membranes toward the end of gestation. Apart from the revealed role of cortisol regeneration, a decline in the density of mesenchymal cells (Casey \& MacDonald 1996) and accumulation of proinflammatory cytokines may also contribute to the reduction in collagen abundance in the fetal membranes during membrane rupture. Enhanced proinflammatory cytokine production has been observed in the fetal membranes at both infection- and noninfection-induced labor (Keelan et al. 2003, GomezLopez et al. 2010, Romero et al. 2014, Lim et al. 2015). Proinflammatory cytokines have been demonstrated to be potent activators of MMPs (Athayde et al. 1998, Ben David et al. 2008), which degrade extracellular collagens. It is well known that glucocorticoids are classical antiinflammatory hormones exerting potent inhibitory effects on proinflammatory cytokines and MMPs in other parts of the body (Vincenti \& Brinckerhoff 2002, Rhen \& Cidlowski 2005). Glucocorticoids have also been shown to inhibit proinflammatory cytokine expression in human 
amnion-derived WISH cells (Keelan et al. 1997). Despite the apparent contradictory anti-inflammatory effects of glucocorticoids, glucocorticoids nonetheless exert potent degradation of collagens in amnion fibroblasts, which suggest that glucocorticoids can degrade collagens independent of the effects on proinflammatory cytokines although we are yet unclear about the effects of glucocorticoids on MMPs in amnion fibroblasts. It remains an interesting question about the interactions of glucocorticoids and proinflammatory cytokines in terms of collagen degradation in the amnion. Is cortisol regeneration or proinflammatory cytokine accumulation dominant in collagen degradation or both contributes to collagen degradation in the amnion during membrane rupture at parturition? Given that proinflammatory cytokines can enhance cortisol regeneration by $11 \beta-H S D 1$ in amnion fibroblasts (Sun \& Myatt 2003, Li et al. 2006), we speculate that proinflammatory cytokines accumulated in inflammation may at least intensify the degradation of collagens by cortisol in the amnion fibroblasts in this regard.

In conclusion, this study has demonstrated that cortisol regenerated by $11 \beta-\mathrm{HSD} 1$ participates in COL3A1 protein degradation via activation of the ubiquitin-proteasome pathway in the amnion fibroblasts. Taken together all the demonstrated effects of cortisol in extracellular matrix remodeling (Guller et al. 1995, Liu et al. 2016, Wang et al. 2016, Mi et al. 2017), we speculate that the right timing of the activation of the feedforward regeneration of cortisol in the amnion may be an indispensable event for the membrane rupture in parturition at term. However, preterm overactivation of this feedforward regeneration of cortisol may be associated with preterm premature rupture of membranes and consequent preterm birth.

\section{Declaration of interest}

The authors declare that there is no conflict of interest that could be perceived as prejudicing the impartiality of the research reported.

\section{Funding}

This work was supported by National Natural Science Foundation of China (grant numbers 81330018 and 31671566) and National Key R \& D Program of China (2017YFC1001403).

\section{Author contribution statement}

Y B M and $\mathrm{K}$ S designed the study; Y B M, W S W, J W L, C Y Z and Y W W performed the experiments; $\mathrm{H} Y$ analyzed clinical sample analysis; $Y B M$, W S W and K S contributed to writing the manuscript.

\section{References}

Alfaidy N, Li W, MacIntosh T, Yang K \& Challis J 2003 Late gestation increase in 11beta-hydroxysteroid dehydrogenase 1 expression in human fetal membranes: a novel intrauterine source of cortisol. Journal of Clinical Endocrinology and Metabolism 88 5033-5038. (https://doi.org/10.1210/jc.2002-021915)

Athayde N, Edwin SS, Romero R, Gomez R, Maymon E, Pacora P \& Menon R 1998 A role for matrix metalloproteinase-9 in spontaneous rupture of the fetal membranes. American Journal of Obstetrics and Gynecology 179 1248-1253. (https://doi.org/10.1016/S00029378(98)70141-3)

Ben David D, Reznick AZ, Srouji S \& Livne E 2008 Exposure to proinflammatory cytokines upregulates MMP-9 synthesis by mesenchymal stem cells-derived osteoprogenitors. Histochemistry and Cell Biology 129 589-597. (https://doi.org/10.1007/s00418-008-0391-1)

Blencowe H, Cousens S, Oestergaard MZ, Chou D, Moller AB, Narwal R, Adler A, Vera Garcia C, Rohde S, Say L, et al. 2012 National, regional, and worldwide estimates of preterm birth rates in the year 2010 with time trends since 1990 for selected countries: a systematic analysis and implications. Lancet 379 2162-2172. (https://doi. org/10.1016/S0140-6736(12)60820-4)

Bryant-Greenwood GD 1998 The extracellular matrix of the human fetal membranes: structure and function. Placenta 19 1-11. (https://doi. org/10.1016/S0143-4004(98)90092-3)

Cao B, Camden AJ, Parnell LA \& Mysorekar IU 2017 Autophagy regulation of physiological and pathological processes in the female reproductive tract. American Journal of Reproductive Immunology $\mathbf{7 7}$ e12650. (https://doi.org/10.1111/aji.12650)

Casey ML \& MacDonald PC 1996 Interstitial collagen synthesis and processing in human amnion: a property of the mesenchymal cells Biology of Reproduction 55 1253-1260. (https://doi.org/10.1095/ biolreprod55.6.1253)

Casey ML, MacDonald PC \& Mitchell MD 1985 Despite a massive increase in cortisol secretion in women during parturition, there is an equally massive increase in prostaglandin synthesis. A paradox? Journal of Clinical Investigation 75 1852-1857. (https://doi. org/10.1172/JCI111899)

Comincini S, Allavena G, Palumbo S, Morini M, Durando F, Angeletti F, Pirtoli L \& Miracco C 2013 microRNA-17 regulates the expression of ATG7 and modulates the autophagy process, improving the sensitivity to temozolomide and low-dose ionizing radiation treatments in human glioblastoma cells. Cancer Biology and Therapy 14 574-586.

Goel SA, Guo LW, Shi XD, Kundi R, Sovinski G, Seedial S, Liu B \& Kent KC 2013 Preferential secretion of collagen type 3 versus type 1 from adventitial fibroblasts stimulated by TGF-beta/Smad3-treated medial smooth muscle cells. Cellular Signalling 25 955-960. (https://doi.org/10.1016/j.cellsig.2012.12.021)

Gomez-Lopez N, Laresgoiti-Servitje E, Olson DM, Estrada-Gutierrez G \& Vadillo-Ortega F 2010 The role of chemokines in term and premature rupture of the fetal membranes: a review. Biology of Reproduction 82 809-814. (https://doi.org/10.1095/ biolreprod.109.080432)

Guller S, Kong L, Wozniak R \& Lockwood CJ 1995 Reduction of extracellular matrix protein expression in human amnion epithelial cells by glucocorticoids: a potential role in preterm rupture of the fetal membranes. Journal of Clinical Endocrinology and Metabolism $\mathbf{8 0}$ 2244-2250. (https://doi.org/10.1210/jcem.80.7.7608287)

Hasan KM, Rahman MS, Arif KM \& Sobhani ME 2012 Psychological stress and aging: role of glucocorticoids (GCs). Age 34 1421-1433. (https://doi.org/10.1007/s11357-011-9319-0)

Hopgood MF, Clark MG \& Ballard FJ 1981 Stimulation by glucocorticoids of protein degradation in hepatocyte monolayers. Biochemical Journal 196 33-40. (https://doi.org/10.1042/bj1960033) http://jme.endocrinology-journals.org

https://doi.org/10.1530/JME-17-0215
(C) 2018 Society for Endocrinology Published by Bioscientifica Ltd. Printed in Great Britain 
Inobe T \& Matouschek A 2014 Paradigms of protein degradation by the proteasome. Current Opinion in Structural Biology 24 156-164. (https://doi.org/10.1016/j.sbi.2014.02.002)

Keelan JA, Sato T \& Mitchell MD 1997 Regulation of interleukin (IL)-6 and IL- 8 production in an amnion-derived cell line by cytokines, growth factors, glucocorticoids, and phorbol esters. American Journal of Reproductive Immunology 38 272-278. (https://doi. org/10.1111/j.1600-0897.1997.tb00514.x)

Keelan JA, Blumenstein M, Helliwell RJ, Sato TA, Marvin KW \& Mitchell MD 2003 Cytokines, prostaglandins and parturition - a review. Placenta 24 (Supplement A) S33-S46. (https://doi. org/10.1053/plac.2002.0948)

Kumar D, Moore RM, Mercer BM, Mansour JM, Redline RW \& Moore JJ 2016 The physiology of fetal membrane weakening and rupture: insights gained from the determination of physical properties revisited. Placenta 42 59-73. (https://doi.org/10.1016/j. placenta.2016.03.015)

Li W, Gao L, Wang Y, Duan T, Myatt L \& Sun K 2006 Enhancement of cortisol-induced 11beta-hydroxysteroid dehydrogenase type 1 expression by interleukin 1beta in cultured human chorionic trophoblast cells. Endocrinology 147 2490-2495. (https://doi. org/10.1210/en.2005-1626)

Lim R, Barker G \& Lappas M 2015 Activation of AMPK in human fetal membranes alleviates infection-induced expression of proinflammatory and pro-labour mediators. Placenta 36 454-462. (https://doi.org/10.1016/j.placenta.2015.01.007)

Liu C, Guo C, Wang W, Zhu P, Li W, Mi Y, Myatt L \& Sun K 2016 Inhibition of Lysyl oxidase by cortisol regeneration in human amnion: implications for rupture of fetal membranes. Endocrinology 157 4055-4065. (https://doi.org/10.1210/en.2016-1406)

Malak TM, Ockleford CD, Bell SC, Dalgleish R, Bright N \& Macvicar J 1993 Confocal immunofluorescence localization of collagen types I, III, IV, V and VI and their ultrastructural organization in term human fetal membranes. Placenta 14 385-406. (https://doi. org/10.1016/S0143-4004(05)80460-6)

Mi Y, Wang W, Zhang C, Liu C, Lu J, Li W, Zuo R, Myatt L \& Sun K 2017 Autophagic degradation of collagen $1 \mathrm{~A} 1$ by cortisol in human amnion fibroblasts. Endocrinology 158 1005-1014. (https://doi. org/10.1210/en.2016-1829)

Murphy BE 1977 Chorionic membrane as an extra-adrenal source of foetal cortisol in human amniotic fluid. Nature 266 179-181. (https://doi.org/10.1038/266179a0)

Murphy BE 1981 Ontogeny of cortisol-cortisone interconversion in human tissues: a role for cortisone in human fetal development. Journal of Steroid Biochemistry 14 811-817. (https://doi. org/10.1016/0022-4731(81)90226-0)

Oyen ML, Calvin SE \& Landers DV 2006 Premature rupture of the fetal membranes: is the amnion the major determinant? American Journal of Obstetrics and Gynecology 195 510-515. (https://doi.org/10.1016/j. ajog.2006.02.010)

Parry S \& Strauss JF 3rd 1998 Premature rupture of the fetal membranes. New England Journal of Medicine 338 663-670. (https://doi. org/10.1056/NEJM199803053381006)

Rhen T \& Cidlowski JA 2005 Antiinflammatory action of glucocorticoids - new mechanisms for old drugs. New England Journal of Medicine 353 1711-1723. (https://doi.org/10.1056/NEJMra050541)

Romero R, Miranda J, Chaiworapongsa T, Korzeniewski SJ, Chaemsaithong P, Gotsch F, Dong Z, Ahmed AI, Yoon BH, Hassan SS, et al. 2014 Prevalence and clinical significance of sterile intraamniotic inflammation in patients with preterm labor and intact membranes. American Journal of Reproductive Immunology 72 458-474. (https://doi.org/10.1111/aji.12296)

Schoepe S, Schacke H, May E \& Asadullah K 2006 Glucocorticoid therapy-induced skin atrophy. Experimental Dermatology 15 406-420. (https://doi.org/10.1111/j.0906-6705.2006.00435.x)

Skinner SJ, Campos GA \& Liggins GC 1981 Collagen content of human amniotic membranes: effect of gestation length and premature rupture. Obstetrics and Gynecology 57 487-489.

Slattery MM \& Morrison JJ 2002 Preterm delivery. Lancet 360 1489-1497. (https://doi.org/10.1016/S0140-6736(02)11476-0)

Strauss JF 3rd 2013 Extracellular matrix dynamics and fetal membrane rupture. Reproductive Sciences 20 140-153. (https://doi. org/10.1177/1933719111424454)

Sun K \& Myatt L 2003 Enhancement of glucocorticoid-induced 11betahydroxysteroid dehydrogenase type 1 expression by proinflammatory cytokines in cultured human amnion fibroblasts. Endocrinology 144 5568-5577. (https://doi.org/10.1210/en.2003-0780)

Thrower JS, Hoffman L, Rechsteiner M \& Pickart CM 2000 Recognition of the polyubiquitin proteolytic signal. EMBO Journal 19 94-102. (https://doi.org/10.1093/emboj/19.1.94)

Tiganescu A, Tahrani AA, Morgan SA, Otranto M, Desmouliere A, Abrahams L, Hassan-Smith Z, Walker EA, Rabbitt EH, Cooper MS, et al. 2013. 11beta-Hydroxysteroid dehydrogenase blockade prevents age-induced skin structure and function defects. Journal of Clinical Investigation 123 3051-3060. (https://doi.org/10.1172/JCI64162)

Vincenti MP \& Brinckerhoff CE 2002 Transcriptional regulation of collagenase (MMP-1, MMP-13) genes in arthritis: integration of complex signaling pathways for the recruitment of gene-specific transcription factors. Arthritis Research 4 157-164. (https://doi. org/10.1186/ar401)

Wang W, Guo C, Zhu P, Lu J, Li W, Liu C, Xie H, Myatt L, Chen ZJ \& Sun K 2015 Phosphorylation of STAT3 mediates the induction of cyclooxygenase-2 by cortisol in the human amnion at parturition. Science Signaling 8 ra106. (https://doi.org/10.1126/scisignal. aac6151)

Wang W, Liu C \& Sun K 2016 Induction of amnion epithelial apoptosis by cortisol via tPA/plasmin system. Endocrinology 157 4487-4498. (https://doi.org/10.1210/en.2016-1464)

Yang Z, Guo C, Zhu P, Li W, Myatt L \& Sun K 2007 Role of glucocorticoid receptor and CCAAT/enhancer-binding protein alpha in the feed-forward induction of 11beta-hydroxysteroid dehydrogenase type 1 expression by cortisol in human amnion fibroblasts. Journal of Endocrinology 195 241-253. (https://doi. org/10.1677/JOE-07-0303)

Yao W, Dai W, Jiang JX \& Lane NE 2013 Glucocorticoids and osteocyte autophagy. Bone 54 279-284. (https://doi.org/10.1016/j. bone.2013.01.034)

Zhao X, Dong X, Luo X, Pan J, Ju W, Zhang M, Wang P, Zhong M, Yu Y, Brown WT \& Zhong N 2017 Ubiquitin-proteasome-collagen (CUP) pathway in preterm premature rupture of fetal membranes. Frontiers in Pharmacology 8 310. (https://doi.org/10.3389/fphar.2017.00310)

Zhu XO, Yang Z, Guo CM, Ni XT, Li JN, Ge YC, Myatt L \& Sun K 2009 Paradoxical stimulation of cyclooxygenase-2 expression by glucocorticoids via a cyclic AMP response element in human amnion fibroblasts. Molecular Endocrinology 23 1839-1849. (https://doi.org/10.1210/me.2009-0201) http://jme.endocrinology-journals.org https://doi.org/10.1530/JME-17-0215 (c) 2018 Society for Endocrinology Published by Bioscientifica Ltd. Printed in Great Britain
Received in final form 27 November 2017

Accepted 30 November 2017

Accepted Preprint published online 30 November 2017 